\title{
COUP-TFII Is Preferentially Expressed in the Caudal Ganglionic Eminence and Is Involved in the Caudal Migratory Stream
}

\author{
Shigeaki Kanatani, Masato Yozu, Hidenori Tabata, and Kazunori Nakajima \\ Department of Anatomy, Keio University School of Medicine, Tokyo 160-8582, Japan
}

While the cortical interneurons derived from the medial ganglionic eminence (MGE) migrate rather diffusely into the cortex, interneurons that migrate out from the caudal ganglionic eminence (CGE) mainly move caudally into the caudal cerebral cortex and the hippocampus in the form of the caudal migratory stream (CMS) (Yozu et al., 2005). Although transplantation experiments at embryonic day 13.5 had revealed that the migrating cells in these two populations are already intrinsically different in regard to their ability to respond to the CGE environment (Yozu et al., 2005), it is not known how the CGE cells are specified and how their migratory behavior is determined.

In this study we showed that, although CGE and lateral ganglionic eminence (LGE) express almost the same marker molecules, LGE cells do not migrate caudally when transplanted into the CGE, suggesting that LGE cells are intrinsically different from CGE cells. We therefore compared the transcriptomes of the CGE, MGE, and LGE, and the results showed that COUP-TFII was expressed preferentially in the CGE as well as in the migrating interneurons in the CMS. Transplantation experiments revealed that COUP-TFII is sufficient to change the direction of MGE cell migration to caudal when transplanted into the CGE environment, and knockdown of COUP-TFII inhibited the caudal migration of the CGE cells. These results suggest that COUP-TFII is both required and sufficient for the CGE-cellspecific migratory behavior in the caudal direction. Thus, a locally expressed transcription factor determines the migratory direction of the cortical interneurons in a region-specific manner.

Key words: GABAergic neuron; migration; transcription factor; cortex; calretinin; development

\section{Introduction}

The cerebral cortex contains two major neuronal populations, excitatory projection neurons and inhibitory interneurons. While projection neurons migrate radially from the cortical ventricular and subventricular zones, interneurons are known to migrate tangentially from the ganglionic eminence (GE). The GE is subdivided into three major proliferative regions, a medial GE (MGE), a lateral GE (LGE), and a caudal GE (CGE), based on anatomical and gene expression profiles (Casarosa et al., 1999; Sussel et al., 1999; Corbin et al., 2000; Puelles et al., 2000; Nery et al., 2002; Flames et al., 2007). Although all three regions give rise to interneurons, the destinations of the migrating neurons derived from each region differ. The LGE-derived neurons migrate to the striatum and olfactory bulb, and the MGE-derived inter-

\footnotetext{
Received May 9, 2008; revised Nov. 1, 2008; accepted Nov. 6, 2008.

This work was supported by the Japan Society for the Promotion of Science, the Ministry of Education, Culture, Sports, and Science and Technology of Japan, the Ichiro Kanehara Foundation, the Tokyo Biochemical Research Foundation, the Sumitomo Foundation, the Uehara Memorial Foundation, the Novartis Foundation, Takeda Science Foundation, Keio University Grant-in-Aid for Encouragement of Young Medical Scientists, and the Brain Science Foundation. S.K. is a Research Fellow of the Japan Society for the Promotion of Science. We are grateful to Dr. Jun-ichi Miyazaki for the CAG-GS plasmid and Drs. Koji Oishi and Daisuke H. Tanaka for valuable discussion and critical reading of this manuscript.

Correspondence should be addressed to Kazunori Nakajima, Department of Anatomy, Keio University School of Medicine, 35 Shinanomachi, Shinjuku-ku, Tokyo 160-8582, Japan. E-mail: kazunori@sc.itc.keio.ac.jp. DOI:10.1523/JNEUROSCI.2132-08.2008

Copyright $\odot 2008$ Society for Neuroscience ～0270-6474/08/2813582-10\$15.00/0
}

neurons migrate dorsolaterally and become widely distributed throughout the neocortex (Lavdas et al., 1999; Sussel et al., 1999; Wichterle et al., 2001; Nery et al., 2002; Borrell et al., 2005; Yozu et al., 2005). The CGE-derived interneurons, on the other hand, have been shown to populate the neocortex, hippocampus, and amygdala (Nery et al., 2002).

We recently reported that interneurons that migrate out from the CGE move caudally into the caudal cortex and the hippocampus in the form of caudal migratory stream (CMS) (Yozu et al., 2005). Transplantation experiments have suggested that the mechanisms controlling the direction of migration of the CGE cells and MGE cells from the subpallium to the developing neocortex are intrinsically different, at least on embryonic day 13.5 (E13.5) (Yozu et al., 2005). However, the molecular mechanisms that regulate the caudal migration of CGE cells have yet to be discovered.

Several genes are known to be expressed in the MGE and not to be expressed in the LGE/CGE (Grigoriou et al., 1998; Sussel et al., 1999). One of them, $N k x 2.1$, is thought to regulate the proliferation of MGE cells, and another, LhxG, is involved in the neuronal migration from the MGE (Sussel et al., 1999; Alifragis et al., 2004; Liodis et al., 2007). However, no genes that specify and determine the unique features of CGE cells have been identified. To determine how LGE cells, which would normally migrate from the LGE region rostrally (rostral migratory stream) or to the 
striatum in vivo (Wichterle et al., 2001; Borrell et al., 2005), would behave in the CGE environment, we heterotopically transplanted LGE cells into the CGE in this study. Since the results showed that the migratory properties of LGE cells are already intrinsically different from those of CGE cells at E13.5, we screened for molecules that are specifically expressed in the CGE and not expressed in the MGE/LGE, and the results showed that COUPTFII was enriched in the CGE. The results of this study show that COUP-TFII is sufficient and required for the caudal migration of interneurons, suggesting that COUP-TFII plays an important role in specifying the unique migratory behavior of CGE cells.

\section{Materials and Methods}

Animals. Pregnant ICR mice were purchased from Japan SLC. All animal experiments were performed according to the guidelines of the Japan Neuroscience Society and Keio University School of Medicine. The day on which a vaginal plug was detected was recorded as embryonic day (E) 0 .

Plasmid vector and siRNA. The CDNA of COUP-TFII derived from a FANTOM cDNA clone (clone ID: B230309B05) was inserted into the pCAG-GS plasmid (CAG-COUP-TFII) (Niwa et al., 1991; Carninci et al., 2005). The siRNAs for COUP-TFII and control siRNAs were purchased from Dharmacon (GE Healthcare Bio-Sciences) as a siRNA SMARTpool reagent (ONTARGET plus), containing a mixture of four different siRNAs with modifications for a single target gene to minimize off-target effects (Birmingham et al., 2006; Jackson et al., 2006). A fluorescein isothiocyanate (FITC)-labeled oligonucleotide (5'-FITC-TACGTACGTACGTA-3') was used as a marker of the site of electroporation as described previously (Yozu et al., 2005).

Focal electroporation into the telencephalic hemisphere. Focal electroporation and hemisphere culture were performed as reported previously (Yozu et al., 2005). Briefly, telencephalic hemispheres from E13.5 ICR mouse embryos were dissected out in PBS. The vectors or siRNAs were mixed with a DsRed-Express expression vector (Clontech) containing a CAG promoter (Niwa et al., 1991) so that the ratio of the vectors (or siRNAs) to the DsRed-Express expression vector would be 1:2. To rescue the effect of siRNAs for COUP-TFII, we used the DsRed-Express Expression vector, siRNAs, and CAG-COUP-TFII in a ratio of 1:1:1. To monitor the injection site, a Fast Green solution ( $0.1 \%$; Sigma) was added to the plasmid solution in a ratio of 1:10 as reported previously (Tabata and Nakajima, 2001; Yozu et al., 2005). Approximately $0.1 \mu \mathrm{l}$ of the plasmid solution $(5 \mu \mathrm{g} / \mu \mathrm{l})$ was injected into the LGE, MGE, or CGE with a glass micropipette. The telencephalic hemispheres were placed between a platinum plate electrode and a tungsten needle electrode. Electronic pulses $(100 \mathrm{~V}, 5 \mathrm{~ms})$ were discharged four times $5 \mathrm{~ms}$ apart with an electroporator (CUY21E; NepaGene), and this series of four electroporations was repeated three times for each hemisphere.

Whole telencephalic hemisphere culture. Electroporated E13.5 telencephalic hemispheres were cultured for $40-42 \mathrm{~h}$ as previously described (Yozu et al., 2005). Brains were rotated in $2 \mathrm{ml}$ of DMEM nutrient mixture/Ham's F-12 (Sigma) containing the N-2 supplement (Invitrogen) under a continuous gas flow $\left(95 \% \mathrm{O}_{2}\right.$ and $5 \% \mathrm{CO}_{2}$ at $37^{\circ} \mathrm{C}$ ) (Nagata and Terashima, 1994). Images of the whole-mount telencephalic hemispheres were acquired with a CCD camera (C5810; Hamamatsu) connected to a fluorescent dissecting microscope (MZFLIII; Leica) or with a color cooled CCD camera (VB-7010; KEYENSE).

Ganglionic eminence hemisphere transplantation. As previously described (Yozu et al., 2005), small fragments of the ventricular zone or subventricular zone from the electroporated E13.5 LGE, MGE, or CGE were dissected out and transplanted into a small hole made in the CGE of the recipient E13.5 telencephalic hemispheres, and the hemispheres were cultured for $40-42 \mathrm{~h}$ as described above.

GeneChip analysis. The central regions of the LGE, MGE, and CGE were dissected out at E13.5 in Dulbecco's PBS. The tissues obtained was rinsed in Dulbecco's PBS three times to prevent cross-contamination and then quickly frozen in liquid nitrogen. RNA isolation and microarray analyses with GeneChip were performed as described previously (Tachikawa et al., 2008). Briefly, total RNA was extracted from the dissected tissue with an RNeasy Mini kit (Qiagen). The quality of the RNA obtained was assessed with a Bioanalyzer 2100 (Agilent Technologies).
Five micrograms of total RNA was converted to cDNA, and biotinlabeled cRNAs were synthesized to be used for hybridization with Mouse Expression set $430 \mathrm{~A}$ and B chips (Affymetrix) according to the manufacturer's protocol. Signals were analyzed using Microarray Suite 6.0 software (Affymetrix).

Whole-mount in situ hybridization. Telencephalic hemispheres were dissected on E13.5 and fixed in 4\% paraformaldehyde (PFA). After washing in $1 \%(\mathrm{v} / \mathrm{v})$ Tween 20 in PBS (PBT), the hemispheres were dehydrated by sequential immersion in $25 \%, 50 \%, 75 \%$, and $100 \%$ methanol solutions. The hemispheres were then sequentially rehydrated in methanol/PBT and bleached in 6\% hydrogen peroxide in PBS for $1 \mathrm{~h}$. Next, the hemispheres were treated with $10 \mu \mathrm{g} / \mathrm{ml}$ proteinase $\mathrm{K}$ for $15 \mathrm{~min}$ to unmask the target RNAs, and then postfixed with $0.2 \%$ glutaraldehyde/4\% PFA in PBT for 20 min. Hybridizations were performed in 50\% formamide, $5 \times \mathrm{SSC}, \mathrm{pH} 4.5,1 \% \mathrm{SDS}, 50 \mu \mathrm{g} / \mathrm{ml}$ yeast RNA, and $50 \mu \mathrm{g} / \mathrm{ml}$ heparin for $16 \mathrm{~h}$ at $70^{\circ} \mathrm{C}$. After the hybridizations, the hemispheres were washed in $50 \%$ formamide $/ 5 \times$ SSC at $70^{\circ} \mathrm{C}$, and in $1 \%$ SDS, $2 \times$ SSC, $1 \%$ $(\mathrm{v} / \mathrm{v})$ Tween 20 at $65^{\circ} \mathrm{C}$. The hemispheres were then washed in $1 \%(\mathrm{v} / \mathrm{v})$ Tween 20 in TBS (TBST), and blocked in TBST with $10 \%(\mathrm{v} / \mathrm{v})$ heatinactivated sheep serum, $1 \%(\mathrm{w} / \mathrm{v})$ bovine serum albumin, $0.1 \%(\mathrm{v} / \mathrm{v})$ Tween 20 for $90 \mathrm{~min}$. The signal was detected with alkaline phosphataseconjugated Fab fragments of anti-digoxigenin (DIG) antibody (1:2000; Roche Diagnostics) in 1\% sheep serum/TBST and substrate solution containing 5-bromo-4-chloro-3-indolyl phosphate (BCIP) and nitro blue tetrazolium (NBT). Images were captured with a color cooled CCD camera (VB-7010; KEYENSE).

DIG-labeled antisense RNA probes were synthesized with DIG-UTPs (Roche Diagnostics) by using PCR products that had been amplified from the FANTOM clones (Ajioka et al., 2006; Tachikawa et al., 2008). The FANTOM cDNA clones were established by the Genome Exploration Research Group, RIKEN GSC, by using the full-length technologies described previously(Carninci et al., 2005), and the clones were replicated and provided by Dnaform.

Immunohistochemistry. The immunohistochemical analyses were performed as described previously (Tabata and Nakajima, 2001; Yozu et al., 2005). The primary antibodies used in this study were anti-calbindin (rabbit polyclonal, 1:1000; Swant), anti-COUP-TFII (mouse monoclonal, 1:100; Perseus Proteomics), anti-calretinin (rabbit polyclonal, 1:1000; Chemicon), anti-somatostatin (rat monoclonal 1:50; Chemicon), and anti-parvalbumin (rabbit polyclonal, 1:1000; Abcam). In brief, anesthetized animals on ice were fixed by transcardial perfusion with $4 \%$ PFA in $0.1 \mathrm{~m}$ sodium phosphate buffer, $\mathrm{pH}$ 7.4. For immunostaining, horizontal sections (14 $\mu \mathrm{m}$ thick) were prepared with a cryostat (CM1900; Leica) and incubated overnight with the primary antibodies. After washing, the sections were incubated with FITC-conjugated antimouse IgG (1:100; Cappel) and tetramethylrhodamine isothiocyanate (TRITC)-conjugated anti-rabbit IgG (1:200; Jackson ImmunoResearch) as the secondary antibodies. Images were acquired with a confocal microscope (FV300; Olympus).

Verification of siRNA efficiency. To assess the efficiency of the siRNAs for COUP-TFII, we electroporated siRNAs into HEK293T cells with a Cell Line Nucleofector Kit V (Amaxa Biosystems). The siRNAs were used according to the instructions included with the siRNA test kit (Amaxa Biosystems). More specifically, $0.5 \mu \mathrm{g}$ of CAG-COUP-TFII and $1 \mu \mathrm{l}$ of siRNAs $(100 \mu \mathrm{M})$ or control siRNAs $(100 \mu \mathrm{M})$ was added to the nucleofector solution and used for transfection into $1.0 \times 10^{6}$ cells each time. The transfected cells were then cultured for $24 \mathrm{~h}$ before fixation. To standardize the number of transfected cells, $0.5 \mu \mathrm{g}$ of DsRed-Express expression vector (Clontech) was also added to the nucleofector solution. After fixation in 4\% PFA for $30 \mathrm{~min}$, immunocytochemistry was performed as described above.

Statistical analysis. Data were evaluated for significant differences by means of a two-tailed Student's $t$ test.

\section{Results}

LGE cells and CGE cells exhibit different migration properties when transplanted into the CGE at E13.5

In a previous study in which we used focal electroporation in combination with whole-mount telencephalic hemisphere cul- 
tures, we showed that when E13.5 MGE cells were heterotopically transplanted into the E13.5 CGE, the MGE cells migrated dorsolaterally in the same manner as they normally move from the MGE (Yozu et al., 2005). In contrast, homotopic transplantation of E13.5 CGE cells into the E13.5 CGE revealed that the transplanted CGE cells migrated caudally along the CMS (Yozu et al., 2005). Thus, the CGE cells appear to have acquired different intrinsic mechanisms causing them to behave differently from MGE cells by E13.5. Since the CGE and LGE tend to share gene expression profiles (Corbin et al., 2003; Stenman et al., 2003; Wonders and Anderson, 2006; Flames et al., 2007; Nakajima, 2007), to identify the molecular basis responsible for CGE cells moving caudally, we first investigated whether LGE cells would also migrate caudally when heterotopically transplanted into the CGE environment. We focally introduced a DsRedExpress-expression plasmid with Fast Green and FITC-labeled oligonucleotides into the central region of the LGE or the dorsal region of the CGE at E13.5, and then used the Fast Green or FITC as a marker to dissect out the transfected cells (Fig. $1 A, B$ for LGE). The cells were then transplanted into the E13.5 CGE (Fig. 1C), and the whole telencephalic hemispheres were cultured for $40-42 \mathrm{~h}$. When CGE cells were transplanted into the CGE $(n=$ 3 ), the labeled cells migrated caudally from the transplanted site as previously described (Fig. 1D-F) (Yozu et al., 2005). However, when LGE cells were transplanted into the CGE, only slight migration was observed from the transplanted site $(n=4)$ (Fig. $1 G-J)$. To obtain quantitative data we counted the number of cells that had migrated $>500 \mu \mathrm{m}$ from the transplantation site. The results showed that a significantly smaller number of LGE-derived cells than transplanted CGE cells migrated $>500 \mu \mathrm{m}$ (Fig. 1), suggesting that, at least by E13.5, the CGE cells had acquired intrinsic migration mechanisms that were different from those of MGE cells and LGE cells.

\section{COUP-TFII is highly enriched in the CGE}

As mentioned above, the gene expression profiles of CGE cells and LGE cells largely overlap. For example, ER81 and Gsh2 are expressed in both the CGE and LGE but not in the MGE (Corbin et al., 2003; Stenman et al., 2003; Wonders and Anderson, 2006; Flames et al., 2007; Nakajima, 2007). On the other hand, several MGE-specific genes has been reported, one of which, $L h x 6$, has been shown to be expressed in MGE-derived interneurons, and inhibition or knock-out of this gene causes a migration defect (Grigoriou et al., 1998; Lavdas et al., 1999; Alifragis et al., 2004; Liodis et al., 2007). We therefore hypothesized that there is a gene similar to $\operatorname{Lh} x 6$ that intrinsically determines the distinct migratory behavior of CGE cells. To search for such a gene, which is
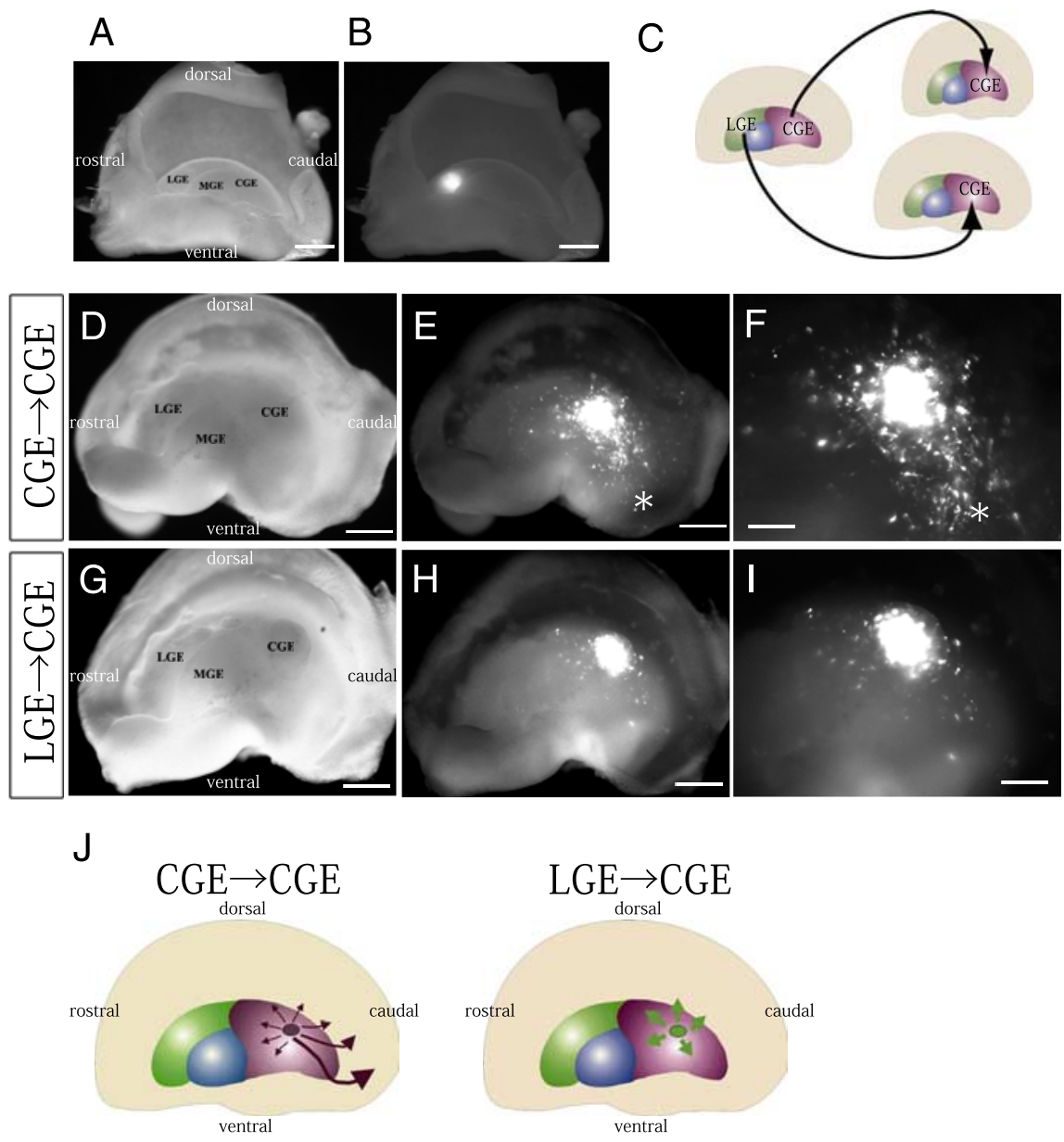

Figure 1. LGE cells behave differently from CGE cells when transplanted into the local environment of the CGE. $A, B$, Median view of the hemispheres. Focal electroporation of FITC-labeled oligonucleotides into the E13.5 LGE. Bright-field (A) and fluoresthan transplanted CGE cells (63.4 $\pm 7.9 \%$ [SE], 3 independent experiments) had migrated $>500 \mu \mathrm{m}(p=0.0076)$.J. Summary of the experiments in which LGE cells or CGE cells were transplanted into the CGE. Scale bars: $\boldsymbol{A}, \boldsymbol{B}, \boldsymbol{D}, \boldsymbol{E}, \mathbf{G}, \boldsymbol{H}, 500 \mu \mathrm{m} ; \boldsymbol{F}, \boldsymbol{I}, 200 \mu \mathrm{m}$.

likely to be specifically expressed in the CGE and not expressed in the LGE/MGE at E13.5, we performed microarray analyses with GeneChip. After manually dissecting the LGE, MGE, and CGE at E13.5, their RNAs were subjected to GeneChip analyses. We set two criteria with the Affymetrix Microarray Suite software to identify candidates for genes that are specifically expressed in the CGE: (1) expressed in the CGE ("Present call" for the CGE) but not in the LGE and MGE ("Absent call" for the LGE and MGE), (2) significantly higher expression in the CGE than in the LGE and MGE ("Increase call" for the CGE vs the MGE and for the CGE vs the LGE). As a result, 26 candidate clones that were "specifically" detected in the CGE were identified by the microarray analyses. To examine their expression profiles greater in detail, we performed in situ hybridization of whole-mount E13.5 telencephalic hemispheres by using FANTOM3 clones (Carninci et al., 2005) as the probe templates. The results showed that COUPTFII (Chicken ovalbumin upstream promoter-transcriptional factor II; also known as Nr2f2) was preferentially expressed in the CGE in the GE region and that there were some additional signals 

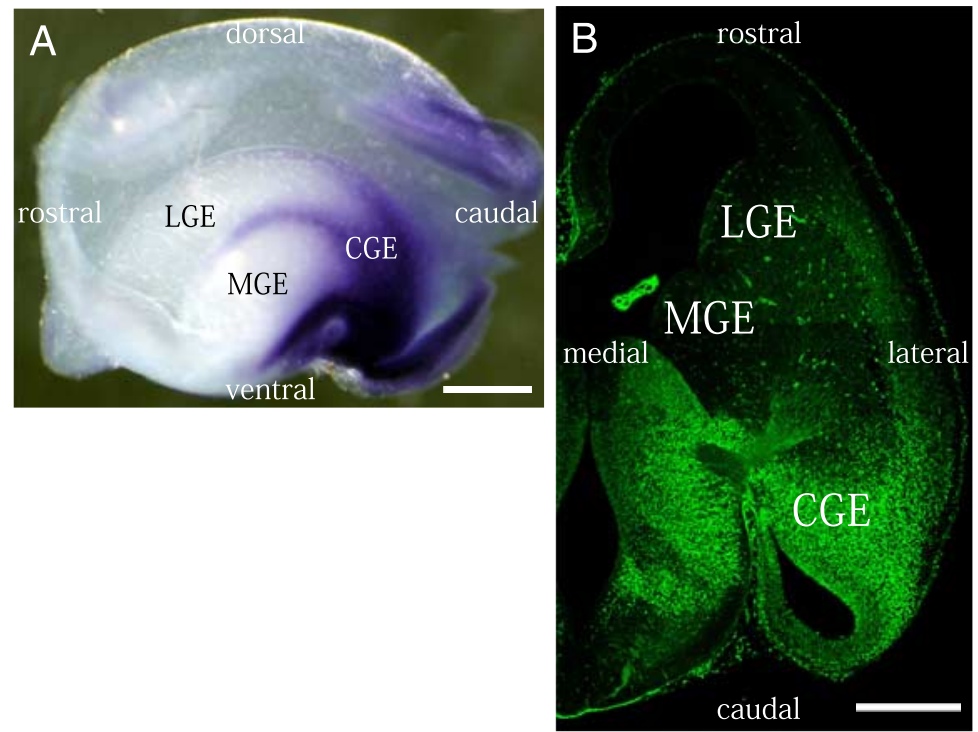

Figure 2. COUP-TFII is preferentially expressed in the CGE. $\boldsymbol{A}$, Whole-mount in situ hybridization of an E13.5 mouse telencephalic hemisphere for COUP-TFII. Median view of the hemisphere is shown. COUP-TFII is preferentially expressed in the CGE in the GE region, and there are some additional signals at the border between MGE and LGE and at the ventral edge of the MGE. $\boldsymbol{B}$, Immunohistochemistry for COUP-TFII on an E13.5 horizontal section. Note that COUP-TFIl protein is detected only in the CGE and that none is detected in the LGE/MGE. Scale bars: $500 \mu \mathrm{m}$.

at the border between the MGE and LGE and at the ventral edge of the MGE (Fig. 2A). To clarify the distribution of COUP-TFII protein, we performed immunohistochemistry on E13.5 horizontal sections with an antibody that had been shown to be specific for COUP-TFII in the previous study (Suh et al., 2006). A strong COUP-TFII signal was detected in the CGE, and a moderate signal was observed in the caudal cortex (Fig. $2 B$ ). In contrast, no signal was observed around the central horizontal levels in the LGE and MGE (Fig. 2 B), indicating that COUP-TFII protein is indeed preferentially produced in the CGE. To better define the distribution of COUP-TFII expression, we performed in situ hybridization and immunohistochemistry on a series of coronal sections at E13.5 (supplemental Fig. 1, available at www. jneurosci.org as supplemental material). A high mRNA signal was detected in the CGE and at the LGE-MGE boundary. A high level of COUP-TFII protein was also observed in the CGE, and a moderate level of distribution was found along the LGEMGE boundary (supplemental Fig. 1E,G, available at www. jneurosci.org as supplemental material).

COUP-TFII is produced by the migrating neurons in the CMS Since a population of calbindin-positive interneurons is known to migrate in the CMS (Fig. 3C) (Yozu et al., 2005), to determine whether COUP-TFII is produced by the migrating interneurons in the CMS, we performed double immunostaining for COUPTFII and calbindin on E13.5 horizontal sections. At E13.5, we observed many calbindin-positive cells migrating out from the CGE (Fig. 3A-C, magenta, arrowheads), and many of them were also labeled for COUP-TFII (Fig. 3D-G, green, arrowheads). The data showed that $71.1 \% \pm 1.4 \%(\mathrm{SE})$ of the calbindin-producing cells in the CMS were positive for COUP-TFII $(n=209,4$ animals). Although the protein level of COUP-TFII tended to decrease before the migrating cells entered the caudal cortex (Fig. $3 \mathrm{~B}, \mathrm{H}-\mathrm{J}$; arrowheads point to cells producing a high amount of COUP-TFII, and arrows point to producing a low amount of COUP-TFII), a large population $(56.8 \pm 4.1 \%$ [SE] $)$ of migrating cells continued to produce a small amount of COUP-TFII even after entering the caudal cortex $(n=96,4$ animals) (Fig. $3 K-N$, arrows). At E15.5, a large population of calbindin-positive cells in the caudal cortex still weakly stained for COUP-TFII (supplemental Fig. 2, available at www.jneurosci.org as supplemental material). These results suggest that expression of COUP-TFII is associated with the CMS.

\section{COUP-TFII is necessary for formation} of the caudal migratory stream

To more directly clarify whether COUPTFII is indeed involved in and required for the caudal migration of CGE cells, we performed siRNA-mediated knockdown of COUP-TFII. We first examined the efficiency of siRNAs against COUP-TFII expression by cotransfecting HEK 293T cells with a CAG-promoter-driven COUPTFII-expression vector (CAG-COUPTFII) and COUP-TFII siRNAs or control siRNAs (supplemental Fig. 3, available at www.jneurosci.org as supplemental material). A CAG-driven DsRed-Express expression vector was also cotransfected to normalize the transfection efficiency. The cells were fixed $24 \mathrm{~h}$ after transfection, and stained with an anti-COUP-TFII antibody. The result was a significant reduction in the ratio between the number of COUP-TFII-positive cells and the number of DsRed-Express-positive cells among the cells electroporated with the COUP-TFII siRNAs than among the cells electroporated with control siRNAs (supplemental Fig. 3, available at www.jneurosci.org as supplemental material). We therefore investigated the effect of siRNAs by performing transplantation experiments in telencephalic hemisphere cultures (Yozu et al., 2005). First, CGE cells in the E13.5 hemisphere were locally electroporated with a DsRed-Express vector and COUP-TFII siRNAs or control siRNAs. The transfected cells were dissected out as small fragments and transplanted into the CGE of another E13.5 hemisphere. After culture for 40-42 h, the transplanted CGE cells in the control experiments were mainly migrating caudally as reported previously (Fig. $4 A, B$, arrow) (Yozu et al., 2005). In contrast, when COUP-TFII had been knocked down with siRNAs, a significantly smaller number of transplanted cells were migrating in the caudal direction (Fig. 4C,D, arrow). Moreover, when the CAG-COUPTFII and siRNAs were cotransfected into the CGE, there was almost complete rescue of the inhibition of the caudal migration by the COUP-TFII-siRNAs (Fig. $4 E, F$, arrow). To perform the quantitative analyses, the cell distribution area was subdivided into four sectors, and the number of cells that had migrated into each sector was counted (Fig. 4G-I). The percentage of COUPTFII-siRNA-transfected cells in sector 4 , which is the region covering the caudal direction, was significantly smaller than in the control ${ }^{*} p=0.0013$; total $n=786$ cells in the control part of the experiments and total $n=526$ cells in the COUP-TFII siRNA part of the experiments, 6 independent experiments) and the COUP-TFIIrescue experiments $\left({ }^{*} p=0.0039\right.$; total $n=191$ cells, 5 independent experiments) (Fig. $4 J$ ). The results confirmed that the COUP-TFII protein level and the number of COUP-TFII-positive cells were decreased by the siRNAs for COUP-TFII (supplemental Fig. 4, available at www.jneurosci.org as supplemental material). These findings 

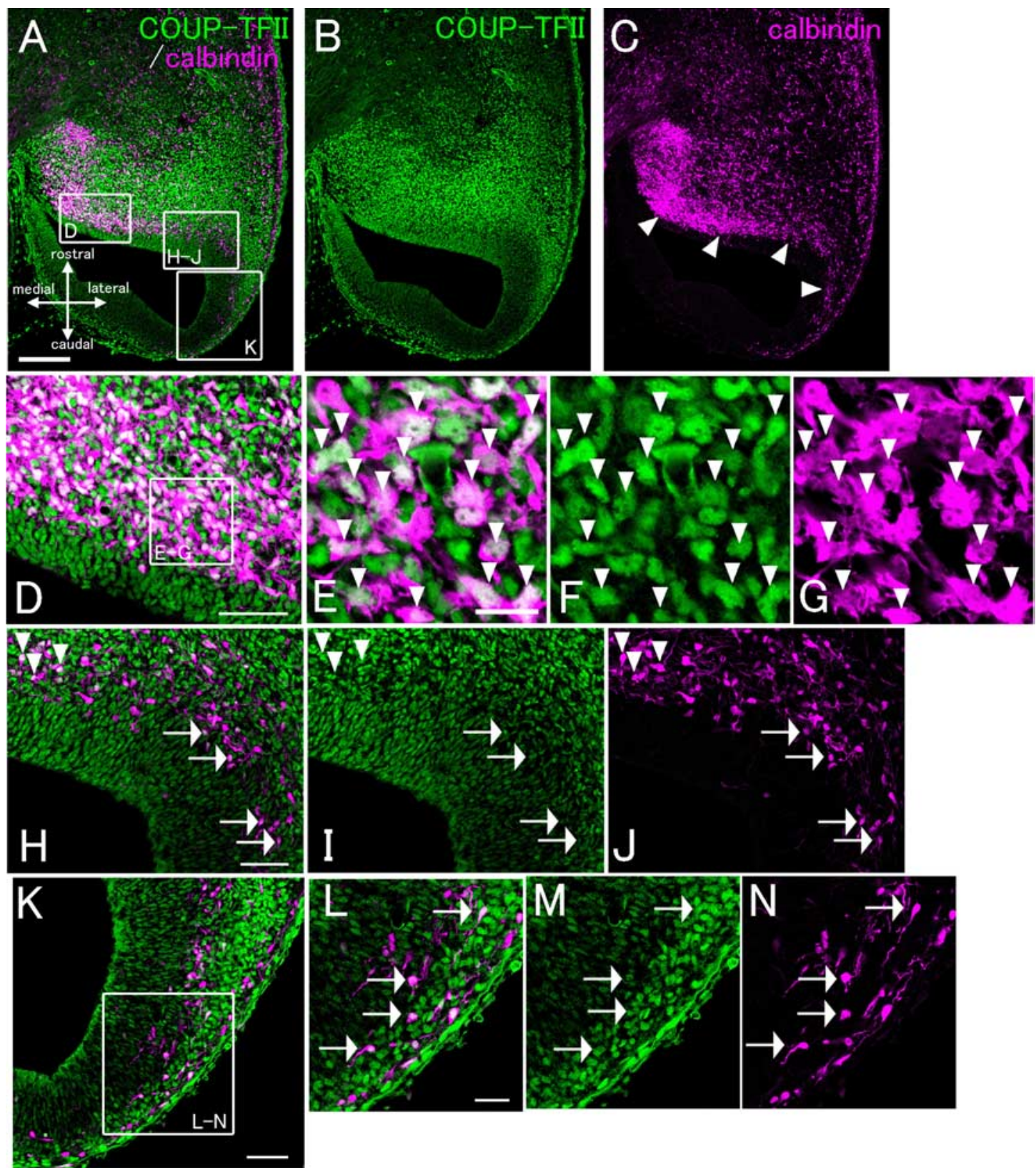

Figure 3. COUP-TFII protein is produced by the migrating neurons in the CMS. A-C, Horizontal sections of E13.5 mouse brains were double-immunostained with an anti-COUP-TFII antibody (green) and an anti-calbindin antibody (magenta). A significant number of calbindin-positive cells contributed to a clear migratory stream from the (GE to the caudal cortex and hippocampus (arrowheads). $\boldsymbol{D}, \boldsymbol{H}-\boldsymbol{J}, \boldsymbol{K}$, Higher magnifications of the boxed areas in A.D-G, A majority of the migrating calbindin-positive neurons were also positive for COUP-TFII (71.1 $\pm 1.4 \%$ [SE], arrowheads in $\boldsymbol{E}-\mathbf{G}$ ). $\boldsymbol{H}-\boldsymbol{J}$, While most of the calbindin-positive cells were strongly labeled with anti-COUP-TFIl before they entered the caudal cortex (arrowheads), the labeling weakened after they entered the caudal cortex (arrows). $K$, A high proportion of the migrating cells in the caudal cortex were still positive for both calbindin and COUP-TFIl (56.8 $\pm 4.1 \%$ [SE]). $L-N$, Higher magnifications of the boxed area in $\boldsymbol{K}$. Representative cells that were double positive for calbindin and COUP-TFIl are indicated by arrows. Scale bars: $\boldsymbol{A}-\boldsymbol{C}, 200 \mu \mathrm{m} ; \boldsymbol{D}, \boldsymbol{H}-\boldsymbol{K}, 50 \mu \mathrm{m} ; \boldsymbol{L}-\boldsymbol{N}, 25 \mu \mathrm{m} ; \boldsymbol{E}-\mathbf{G}, 15 \mu \mathrm{m}$.

suggest that COUP-TFII is necessary for the caudal migration (CMS) of CGE cells.

COUP-TFII is sufficient to cause MGE-derived cells to migrate in the caudal direction in the CGE environment

To investigate the ability of COUP-TFII to induce the formation of the CMS, we overexpressed COUP-TFII in the E13.5 MGE cells and heterotopically transplanted them into the CGE of another E13.5 hemisphere. As reported in our previous study, E13.5 control MGE-derived cells, into which only a DsRed-Express and a control vector had been electroporated, migrated diffusely when transplanted into the E13.5 CGE (Fig. 5A,B,G) (Yozu et al.,
2005). The cells appeared to distribute themselves more ventrally in the GE than in our previous study (Yozu et al., 2005) because we transplanted the MGE cells into a more dorsal part of the CGE in the present study than in our previous experiments. However, when MGE-derived cells transfected with DsRed-Express and COUP-TFII were transplanted into the CGE, the transfected MGE cells migrated caudally (Fig. 5C,D, G). Quantification of the results showed a significant difference between the results after control transfection $(33.4 \pm 2.3 \%[\mathrm{SE}])$ and COUP-TFII transfection $(60.4 \pm 2.0 \%$ [SE] $)$ in sector $4\left({ }^{*} p=0.001\right.$; total $n=$ 249 cells in the control part of the experiments and total $n=318$ cells in the overexpression part of the experiments, 3 independent 

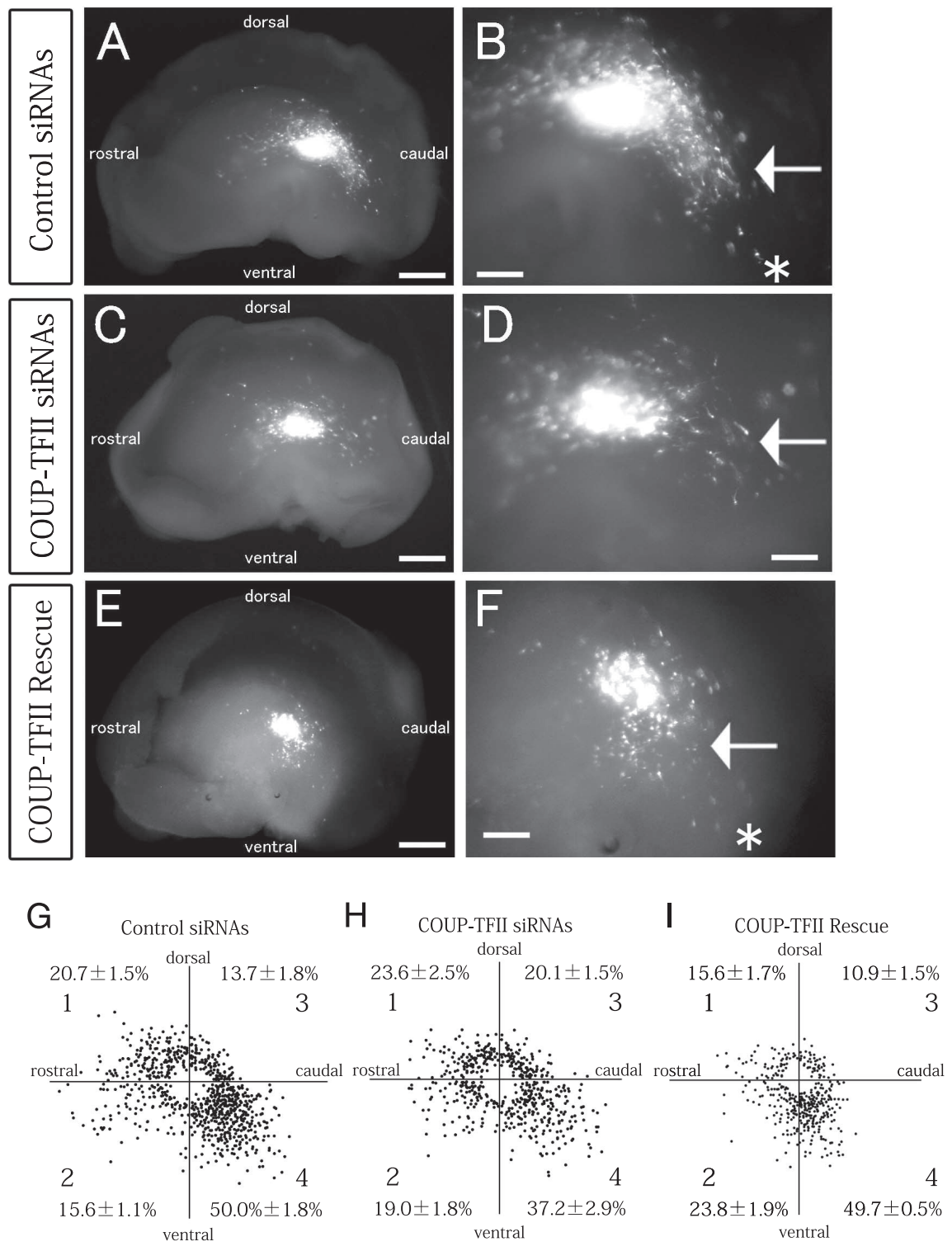

$J$

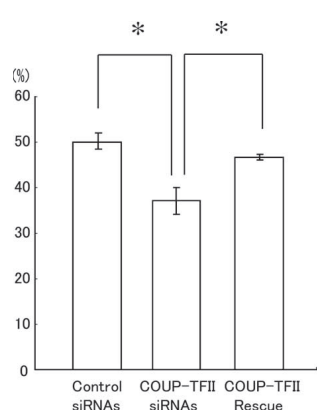

Figure 4. COUP-TFIl is necessary for the formation of the caudal migratory stream. $A-F$, Knockdown and rescue of COUP-TFII in homotopic transplants of (GE cells into the CGE. Median view of the hemispheres. COUP-TFII siRNAs $(\boldsymbol{C}, \boldsymbol{D})$, control siRNAs $(\boldsymbol{A}, \boldsymbol{B})$, or the COUP-TFII siRNAs plus a COUP-TFI-expression vector $(\boldsymbol{E}, \boldsymbol{F})$ were introduced into the mouse E13.5 (GE together with a DsRed-Express vector, and small fragments of the transfected CGE were transplanted into the CGE of other E13.5 telencephalic hemispheres. The hemispheres were then cultured for $40-42 \mathrm{~h} . A, B$, A number of transplanted control cells migrated caudally (indicated by the arrow in $\boldsymbol{B}$ ) toward the caudal end (asterisk in $\boldsymbol{B}$ ). $\boldsymbol{C}, \boldsymbol{D}$, When COUP-TFIl siRNAs were introduced into the transplanted (GE cells, formation of the CMS was significantly inhibited (indicated by an arrow in $\boldsymbol{D}$ ). $\boldsymbol{E}$, $\boldsymbol{F}$, When COUP-TFll siRNAs and a COUP-TFI-expression vector were cointroduced into the transplanted CGE cells, formation of the CMS was significantly rescued (indicated by an arrow in $\boldsymbol{F}$ ), and many transplanted cells migrated caudally toward the caudal end (asterisk in $\boldsymbol{F}$ ). $\boldsymbol{B}, \boldsymbol{D}$, $\boldsymbol{F}$, Higher magnifications of $\boldsymbol{A}, \boldsymbol{C}, \boldsymbol{E}$, respectively. $\boldsymbol{G}-\boldsymbol{I}$, Distribution of the transplanted control CGE cells (G), COUP-TFII siRNAelectroporated CGE cells $(\boldsymbol{H})$, and COUP-TFIl-rescued CGE cells $(\boldsymbol{I})$ in the GE after $40-42 \mathrm{~h}$ in vitro. Each dot represents one cell. The number of migrating cells in each of the four sectors was counted (average \pm SE $[\%] ; 6$ independent experiments for the control experiments) (Fig. 5E,F). These results indicate that COUP-TFII is sufficient to change the migratory direction of MGE-derived cells to caudal, suggesting that the formation of the CMS is regulated by specific expression of COUP-TF11 in the CGE cells.

\section{Calbindin-positive/COUP-TFII- negative cells seem to migrate anterolaterally}

We noticed two distinct subregions containing calbindin-positive cells were present in the E13.5 CGE (Fig. 6). One subregion was located in the caudal part of the CGE (Fig. 6A-C, lower arrowhead), and the majority of the calbindin-positive cells in this subregion were also positive for COUP-TFII (64.4 $\pm 6.8 \%$ [SE]) (Fig. $6 D-F)$. The CMS appeared to be continuous with this subregion (Fig. $6 A, C, J$ ). The other subregion containing calbindinpositive cells, however, was positioned in the rostral part of the CGE (Fig. 6A-C, upper arrowhead), and most of the calbindin-positive cells in this subregion were in fact negative for COUP-TFII, with only $14.4 \pm 3.7 \%$ (SE) staining positive (Fig. 6G-I). Interestingly, most of the migrating calbindin-positive/COUP-TFIInegative cells seemed to move in the anterolateral direction [Fig. 6C (top arrow), $J$, whereas the calbindin-positive/COUPTFII-positive cells migrated caudally in the CMS [Fig. 6C (bottom arrow), J]. These results further supported our hypothesis that COUP-TFII regulates the caudal migration of CGE cells (Fig. $6 \mathrm{~J}$ ).

\section{Cells from the ventral edge of MGE migrate caudally}

As shown in Figure 2A, COUP-TFII is expressed at the ventral edge of the MGE and at the boundary between the MGE and LGE (Fig. 2A; supplemental Fig. 1, available at www.jneurosci.org as supplemental material). To examine whether the cells in these COUP-TFII-positive regions also migrate caudally, we tried performing focal electroporation into the ventral edge of the MGE and the boundary between MGE and LGE. Due to the technical difficulty of local labeling the boundary between the MGE and LGE, we were unable to obtain a reliable migration profile of the cells de-

$\leftarrow$

and COUP-TFIl siRNAs, and 5 independent experiments for COUP-TFII rescue). J, Calculation of the percentages of transplanted cells in sector 4 . In sector 4, the percentage ( \pm SE) of COUP-TFIl siRNA-transfected CGE cells was significantly smaller than the percentage of transplanted control CGE cells $\left({ }^{*} p=0.0013\right)$ and of COUP-TFII-rescued CGE cells $\left({ }^{*} p=\right.$ 0.0039). Scale bars: $A, C, E, 500 \mu \mathrm{m} ; \boldsymbol{B}, \boldsymbol{D}, \boldsymbol{F}, 200 \mu \mathrm{m}$. 
rived from this region (data not shown). However, we found that the cells at the ventral edge of the MGE tended to migrate caudally (Fig. 7A,B). Quantification of the results showed a significant preference toward migration in the caudal direction $(73.2 \pm 3.9 \%$ [SE] in the caudal sector, 4 independent experiments) (Fig. 7C,D). These results further support our conclusion that COUP-TFII regulates caudal migration. The results also strongly suggested that the migrating cells in the CMS included ventral MGE-derived cells that move caudally through the CGE.

\section{Some of the calretinin-positive neurons in the postnatal visual cortex produce COUP-TFII}

Recent studies have revealed that the major population of calretinin-positive interneurons in the postnatal cortex is derived from the embryonic CGE (Xu et al., 2004, 2008; Butt et al., 2005). To investigate whether the CGE-derived calretininpositive neurons in the postnatal cortex produce COUP-TFII, we performed double immunostaining for calretinin and COUP-TFII at P9.5. The results showed that some of the calretinin-positive interneurons in the P9.5 visual cortex were also positive for COUP-TFII (Fig. $8 A-C$ ). Strong COUP-TFII signals were observed in the multipolar/stellate calretininpositive cells in the upper layers (Fig. $8 D-F$, arrowheads), and weak signals were detected in the bipolar calretinin-positive cells (Fig. 8D-F, arrows). Since that the calretinin-positive bipolar cells have been directly shown to be primarily derived from the CGE (Xu et al., 2004, 2008; Butt et al., 2005), at least a subpopulation of the interneurons that migrate from the CGE may continue to produce COUP-TFII even after they settle in the postnatal cortex. We also observed that some of the somatostatin- and calretinin-coexpressing interneurons in the P25 visual cortex were positive for COUP-TFII (supplemental Fig. 5, available at www.jneurosci.org as supplemental material). Some cells were singlepositive cells for COUP-TFII, calretinin, or somatostatin (supplemental Fig. 5, available at www.jneurosci.org as supplemental material). In contrast, we did not observe doublepositive cells for parvalbumin and COUP-

TFII in the P25 visual cortex (supplemental Fig. 6, available at www.jneurosci.org as supplemental material).

\section{Discussion}

Our previous study clarified the three-dimensional migration profiles of interneurons derived from each part of the GE and

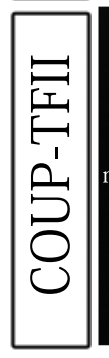

G
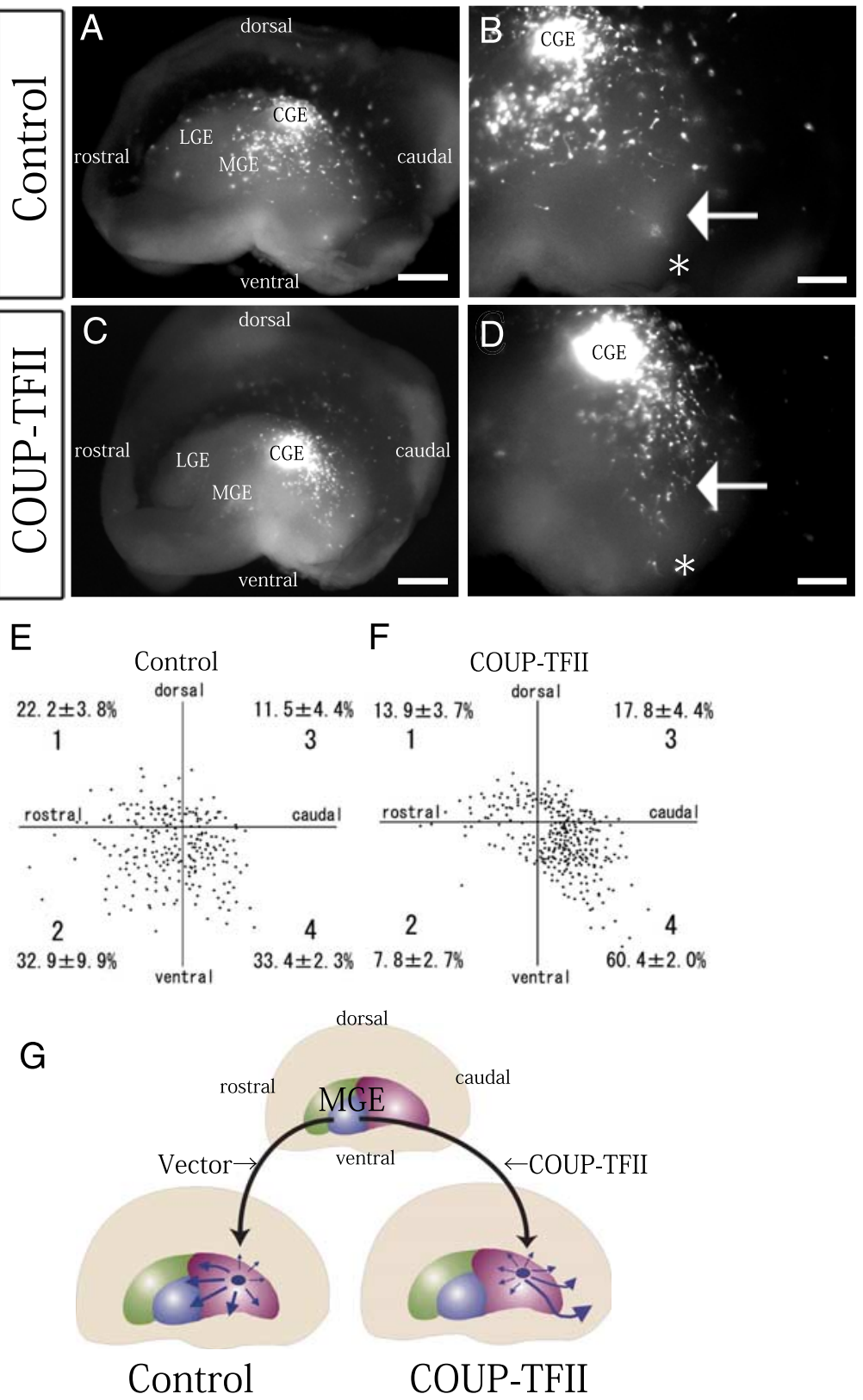

Figure 5. COUP-TFll is sufficient to cause MGE-derived cells to migrate in the caudal direction when transplanted into the CGE environment. $\boldsymbol{A}-\boldsymbol{D}$, Overexpression of COUP-TFII in the MGE cells followed by heterotopic transplantation into the CGE. Median view of the hemispheres. A CAG-driven COUP-TFIl-expression vector $(\boldsymbol{C}, \boldsymbol{D})$ or a control CAG vector $(\boldsymbol{A}, \boldsymbol{B})$ was introduced into the mouse E13.5 MGE together with a DsRed-Express vector, and small fragments of the transfected MGE were transplanted into the CGE of other E13.5 telencephalic hemispheres. The hemispheres were cultured for $40-42 \mathrm{~h}$. $A$, When control MGE cells were transplanted into the CGE, the transplanted cells tended to migrate diffusely. C, When COUP-TFII-transfected MGE cells were transplanted into the CGE, however, the transplanted cells tended to move caudally (note the different numbers of cells in the regions indicated by arrows in $\boldsymbol{B}$ and $\boldsymbol{D}$ ). The caudal ends are indicated by asterisks. $\boldsymbol{B}, \boldsymbol{D}$, Higher magnifications of $\boldsymbol{A}$ and $\boldsymbol{C}$, respectively. $\boldsymbol{E}, \boldsymbol{F}$, Distributions of the transplanted control MGE cells $(E)$ and COUP-TFI-electroporated MGE cells $(\boldsymbol{F})$ in the GE after $40-42 \mathrm{~h}$ in vitro. Each dotrepresents one cell. The number of migrating cells in each of the four sectors was counted (average \pm SE [\%]; 3 independent experiments). $G$, Summary of the migration profiles of the transplanted MGE cells. Scale bars: $A, C, 500 \mu \mathrm{m} ; \boldsymbol{B}, \mathbf{D}, 200 \mu \mathrm{m}$.

showed that the intrinsic property of CGE cells to migrate caudally had been determined by E13.5 (Yozu et al., 2005). In the present study, we demonstrated that COUP-TFII is preferentially expressed in the CGE and regulates the formation of the CMS. These results indicate that a locally expressed transcription factor determines the migratory direction of the cortical interneurons in a region-specific manner. 

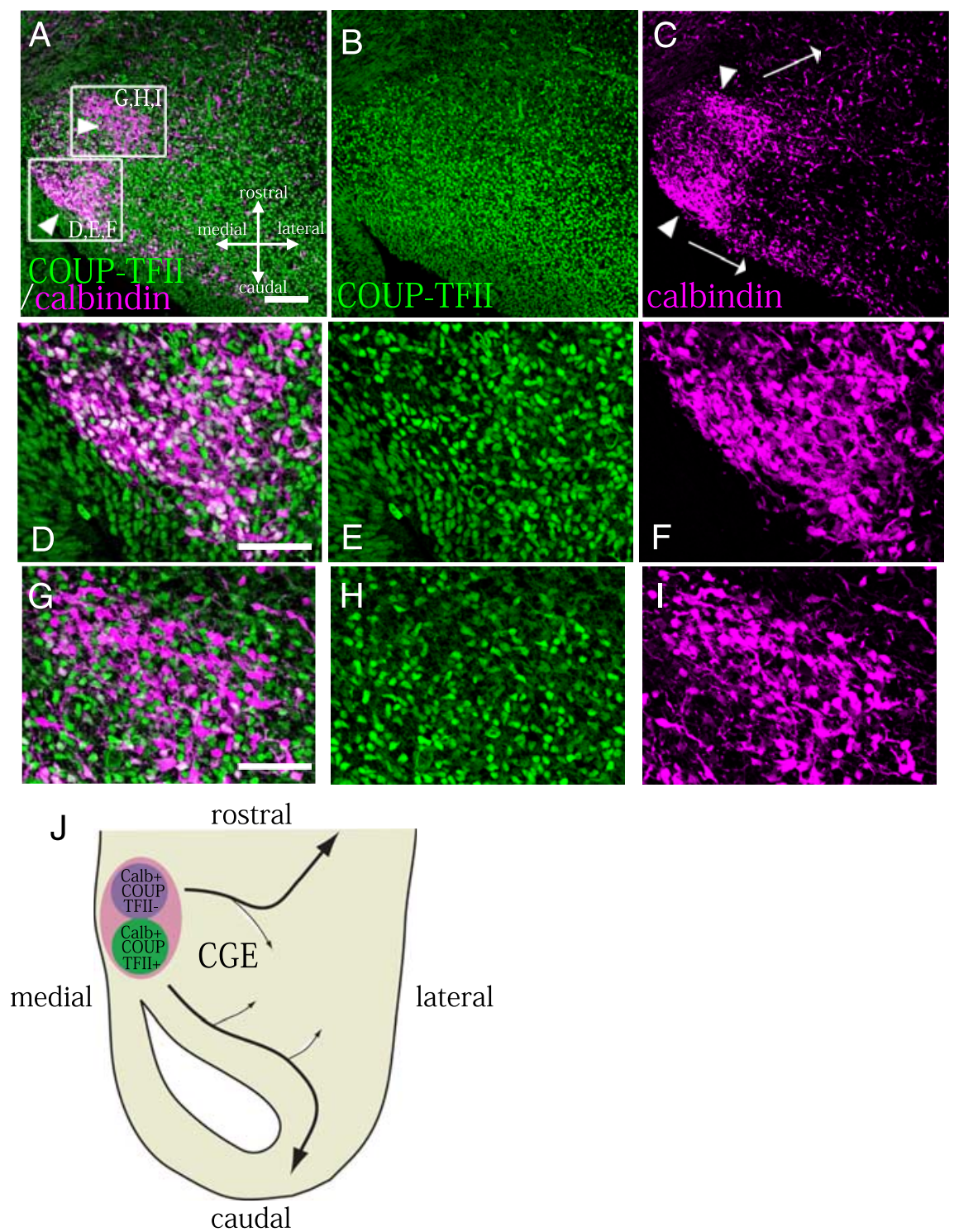

Figure 6. The COUP-TFII-negative/calbindin-positive population of CGE cells tended to migrate anterolaterally in vivo, whereas the COUP-TFII-positive/calbindin-positive population moved in the caudal direction. A-I, Immunostaining of the CGE region for calbindin (magenta) and COUP-TFII (green). $\boldsymbol{A}$-C, There are two cohorts of calbindin-positive cells: a COUP-TFII-positive population (bottom arrowhead) and a COUP-TFII-negative population (top arrowhead). $\boldsymbol{D}-\boldsymbol{I}$, Higher magnifications of the boxed areas in $A$. The majority of the calbindin-positive cells in the caudal part of the CGE were COUP-TFIl positive (64.4 $\pm 6.8 \%$ [SE], 4 animals) ( $\boldsymbol{C}$, bottom arrowhead; $\boldsymbol{D}-\boldsymbol{F})$ and migrated caudally $(\boldsymbol{C}$, bottom arrow), whereas the calbindin-positive cells in the rostral part of the (GE tended to be COUP-TFII-negative (positive cells: $14.4 \pm 3.7 \%$ [SE], 4 animals) ( $\boldsymbol{C}$, top arrowhead; $\boldsymbol{G}-\boldsymbol{I}$ ) and move anterolaterally ( $\boldsymbol{C}$, top arrow).J, Schema of the migratory paths of the calbindin-positive cells in the CGE. Scale bars: $\boldsymbol{A}-\boldsymbol{C}, 100 \mu \mathrm{m}$; $D-I, 50 \mu \mathrm{m}$.

The CGE is a distinct GE region that is characterized by expression of COUP-TFII

Although several molecules are known to be expressed only in the MGE in the GE region, the expression profiles of various markers usually overlap in the LGE and CGE (Corbin et al., 2003; Stenman et al., 2003; Wonders and Anderson, 2006; Flames et al., 2007; Nakajima, 2007). However, the results of our transplantation experiments suggested that E13.5 CGE cells had acquired some intrinsic properties that were distinct from those of LGE/ MGE cells, implying that some molecules specifically function in the CGE region. We therefore performed microarray analyses followed by in situ hybridization in the present study in an attempt to identify such molecules. The results showed that COUPTFII was localized in the CGE, as recently demonstrated by an- other group in a microarray analysis, although morphological verification was not attempted in their study (WilliMonnerat et al., 2008). Recent papers have proposed that the CGE is a caudal extension of the LGE and MGE (Wonders and Anderson, 2006; Flames et al., 2007). However, our results showing that COUP-TFII is preferentially expressed in the CGE and regulates the formation of the CMS suggest that the CGE may be a region that is distinct from the LGE and MGE in the terms of neuronal migration/specification.

In addition to being expressed in the CGE, COUP-TFII is also expressed at the border between MGE and LGE and at the ventral edge of the MGE (Fig. $2 A$; supplemental Fig. 1, available at www.jneurosci. org as supplemental material). Heterotopic transplantation of MGE cells into the CGE in our previous study was followed by dorsolateral migration of the transplanted MGE cells (Yozu et al., 2005). However, in the previous experiments we used the central region of the MGE, where COUP-TFII is not expressed, and the dorsal and ventral edges of MGE were not tested. In the present study, we found that at least the cells at the ventral edge of the MGE tended to move caudally through the CGE to join the CMS (Fig. 7). Thus, at least some of the migrating cells in the CMS are not derived from the CGE but are likely to originate in the MGE.

\section{Migratory direction and characteristics of CGE cells}

Tripodi et al. (2004) reported that, at E13.5, the majority of calbindin-positive cells in the neocortex and piriform cortex were not colabeled with anti-COUP-TFII, whereas we observed that a large population of cells in the CGE and caudal cortex was double positive for calbindin and COUP-TFII. This difference in COUPTFII immunoreactivity may be attributable to the difference in the regions of the brain observed. Tripodi et al. (2004) also homotopically transplanted CGE cells in slice cultures and observed a ventrally migrating stream toward the preoptic area (POa) and hypothalamus. They reported that the ventral stream did not contain COUP-TFII-positive cells. Although the ventral stream is derived from the CGE, the CMS must be different from the ventral stream, because our study indicated that migrating interneurons in the CMS included a high proportion of COUP-TFII-positive cells (Fig. 3). In the present study we also found that some calbindin-positive/ COUP-TFII-negative cells in the CGE seemed to move in the anterolateral direction (Fig. 6). Although the migratory directions and destinations of the CGE cells are multimodal, the results of the present study indicate that at least their caudal migration is regulated by COUP-TFII in the CGE cells. 


\section{Characteristics of \\ COUP-TFII-positive interneurons}

Previous studies indicated that the vertically oriented, bipolar or bitufted subclass of the calretinin-expressing interneurons originate mainly in the dorsal CGE (Xu et al., 2004; Butt et al., 2005). In the present study we showed a population of bipolar interneurons that produce COUP-TFII and calretinin is present in the upper layers of the P9.5 visual cortex (Fig. 8). Previous studies indicated that COUP-TFII is also highly expressed in the amygdaloid nucleus, which some of the CGE cells are destined to populate (Lopes da Silva et al., 1995; Nery et al., 2002; López-Bendito et al., 2004; Tole et al., 2005). We also observed that some of the calretinin-positive cells in the hippocampus are COUP-TFII positive (data not shown). Thus, COUPTFII tends to be strongly highly associated with regions that contain CGE-derived cells.

After homotopically transplanting of E13.5 CGE cells into the CGE, Nery et al. (2002) observed that the transplanted cells were mainly localized in layer $\mathrm{V}$ of the neocortex. They also showed that only a very few calretinin-positive cells were produced by the transplanted CGE cells. In contrast, Butt et al. (2005) found that CGE cells were preferentially distributed in more superficial layers than MGE-derived cells and that approximately one-fourth of the CGE-derived cells expressed calretinin. Our results may reflect both populations in these previous studies, because COUPTFII was expressed in both the deep layers and the superficial layers, and some of the cells located in the upper layers were calretinin-positive cells (Fig. 8). These results are consistent with the findings in the previous studies in which early-born calretinin-positive cells were located preferentially around layers II/III (Yozu et al., 2004; Rymar and Sadikot, 2007)

Recent work has identified a subpopulation of double-positive calretinin- and somatostatin-positive cells that have multipolar/stellate morphology and are derived from the dorsal MGE expressing Nkx6.2 (Fogarty et al., 2007). Our results showed that a population of calretininpositive cells with multipolar/stellate morphology was colabeled with COUP-TFII (Fig. 8). Because the expression profile of COUP-TFII overlaps that of Nkx6.2 in the dorsal edge of the MGE (Fig. 2A; supplemental Fig. 1, available at www.jneurosci. org as supplemental material) and a calretinin/somatostatin-positive population was shown to derive from the Nkx6.2positive region (Fogarty et al., 2007), COUP-TFII may also control the migra-
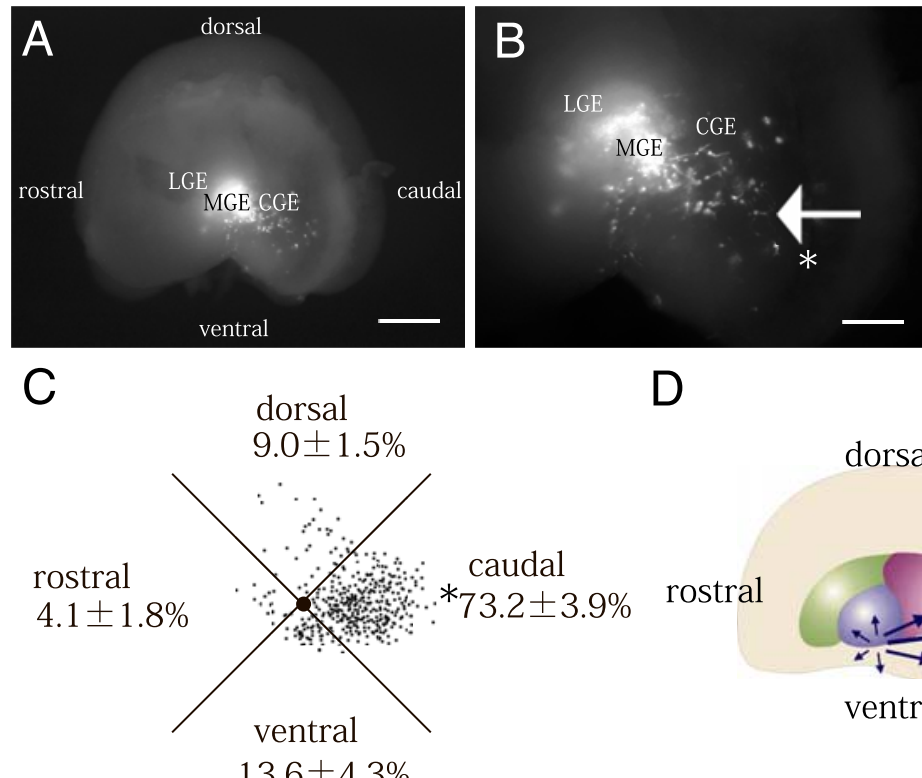

D

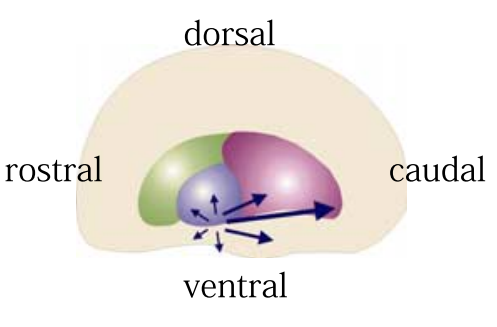

$13.6 \pm 4.3 \%$

Figure 7. Cells from the ventral edge of MGE migrate caudally. $A, B$, Focal electroporation was performed into the ventral edge of the MGE, and the hemispheres were cultured for $40-42 \mathrm{~h}$. $\boldsymbol{B}$, Higher magnifications of $\boldsymbol{A}$. When the cells in the dorsal edge of the MGE were labeled with DsRed-Express, a number of the cells tended to move caudally (indicated by the arrow in $\boldsymbol{B}$ ). The caudal ends are indicated by asterisks in $\boldsymbol{B}$. $\boldsymbol{C}$, Distribution of the cells that migrated out from the ventral edge of the MGE. Each dot represents one cell. The number of migrating cells in each of the four sectors was counted (average \pm SE [\%]; 4 independent experiments). The caudal ends are indicated by asterisks. $D$, Summary of the migration profiles of the cells in the ventral edge of MGE. Scale bars: $A, 500 \mu \mathrm{m} ; \boldsymbol{B}, 200 \mu \mathrm{m}$.
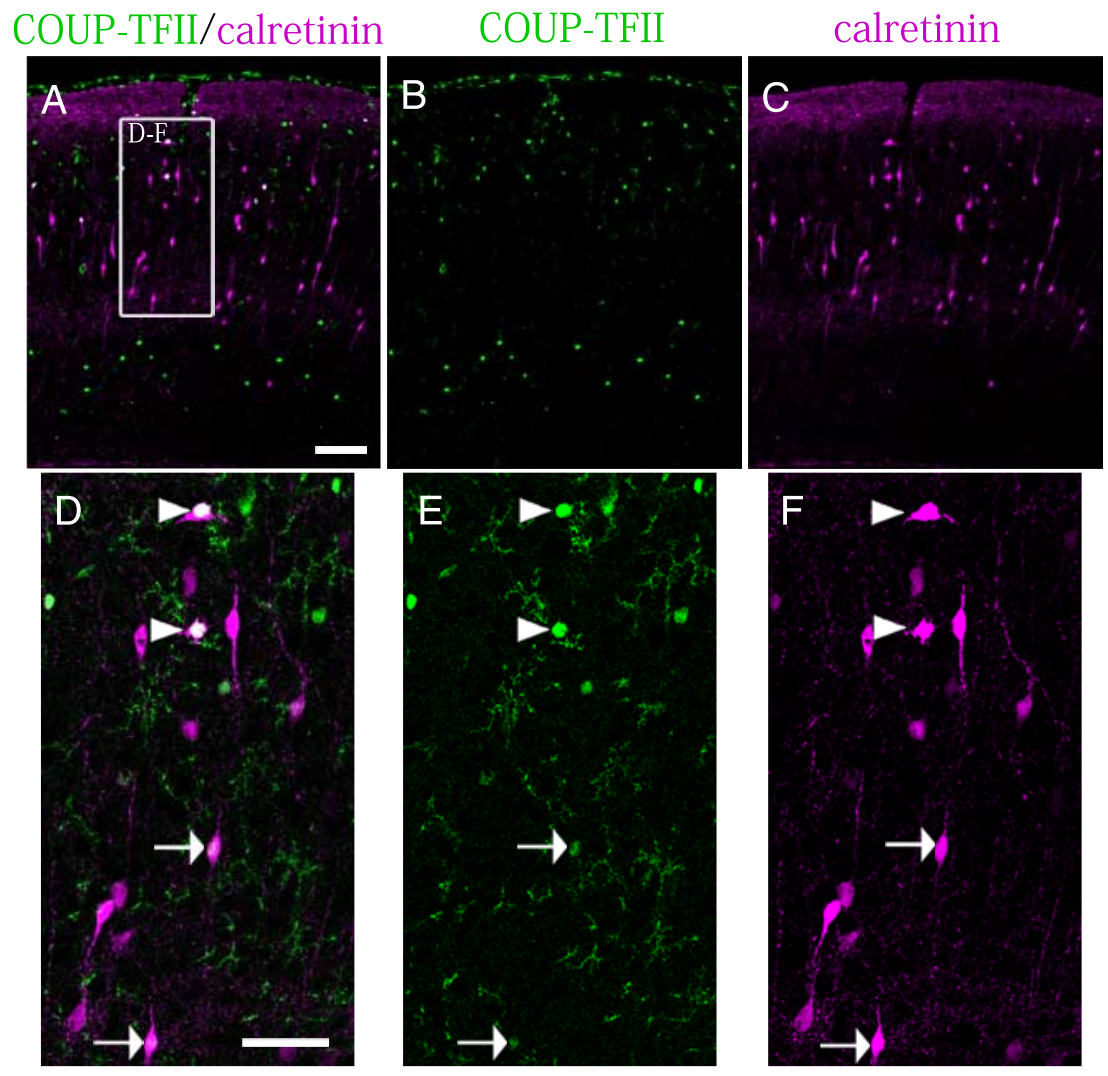

Figure 8. Some of the calretinin-positive neurons in the postnatal visual cortex produce COUP-TFIl. $\boldsymbol{A}-\boldsymbol{C}$, Double immunostaining of the P9.5 visual cortex with antibodies against COUP-TFII (green) and calretinin (magenta). The COUPTFIl-positive population is split into superficial layers and deep layers $(\boldsymbol{A}-\boldsymbol{C}) . \boldsymbol{D}-\boldsymbol{F}$, Higher magnifications of the boxed area in $\boldsymbol{A}$. A strong COUP-TFIl signal was observed in multipolar/stellate calretinin-positive cells in the superficial layers ( $\boldsymbol{D}-\boldsymbol{F}$, arrowheads). Several bipolar-shaped calretinin-positive cells were weakly positive for COUP-TFII (D-F, arrows). Scale bars: $\boldsymbol{A}-\boldsymbol{C}, 100 \mu \mathrm{m} ; \boldsymbol{D}-\boldsymbol{F}, 50 \mu \mathrm{m}$. 
tion and differentiation of the cells in the dorsal edge of the MGE into calretinin-positive multipolar/stellate cells.

COUP-TFII is a transcription factor that is capable of acting as both positive and negative regulators (Park et al., 2003), and a variety of genes are known to be regulated by COUP-TFII (Park et al., 2003). Therefore, some molecules downstream of COUPTFII must sense the direction of migration in the CMS. You et al. (2005) showed that COUP-TFII was specifically expressed in venous endothelium and not expressed in arterial endothelium, and that ablation of COUP-TFII in endothelial cells enabled veins to acquire arterial characteristics by suppressing the expression of neuropilin-1 and Notch signaling molecules. Identification of the downstream molecules of COUP-TFII in the caudally migrating neurons in the future will be important to understanding the regulatory mechanisms of the CMS.

\section{References}

Ajioka I, Maeda T, Nakajima K (2006) Identification of ventricular-sideenriched molecules regulated in a stage-dependent manner during cerebral cortical development. Eur J Neurosci 23:296-308.

Alifragis P, Liapi A, Parnavelas JG (2004) Lhx6 regulates the migration of cortical interneurons from the ventral telencephalon but does not specify their GABA phenotype. J Neurosci 24:5643-5648.

Birmingham A, Anderson EM, Reynolds A, Ilsley-Tyree D, Leake D, Fedorov Y, Baskerville S, Maksimova E, Robinson K, Karpilow J, Marshall WS, Khvorova A (2006) 3' UTR seed matches, but not overall identity, are associated with RNAi off-targets. Nat Methods 3:199-204.

Borrell V, Yoshimura Y, Callaway EM (2005) Targeted gene delivery to telencephalic inhibitory neurons by directional in utero electroporation. J Neurosci Methods 143:151-158.

Butt SJ, Fuccillo M, Nery S, Noctor S, Kriegstein A, Corbin JG, Fishell G (2005) The temporal and spatial origins of cortical interneurons predict their physiological subtype. Neuron 48:591-604.

Carninci P, Kasukawa T, Katayama S, Gough J, Frith MC, Maeda N, Oyama R, Ravasi T, Lenhard B, Wells C, Kodzius R, Shimokawa K, Bajic VB, Brenner SE, Batalov S, Forrest AR, Zavolan M, Davis MJ, Wilming LG, Aidinis V, et al. (2005) The transcriptional landscape of the mammalian genome. Science 309:1559-1563.

Casarosa S, Fode C, Guillemot F (1999) Mash1 regulates neurogenesis in the ventral telencephalon. Development 126:525-534.

Corbin JG, Gaiano N, Machold RP, Langston A, Fishell G (2000) The Gsh2 homeodomain gene controls multiple aspects of telencephalic development. Development 127:5007-5020.

Corbin JG, Rutlin M, Gaiano N, Fishell G (2003) Combinatorial function of the homeodomain proteins $\mathrm{Nkx} 2.1$ and Gsh2 in ventral telencephalic patterning. Development 130:4895-4906.

Flames N, Pla R, Gelman DM, Rubenstein JL, Puelles L, Marín O (2007) Delineation of multiple subpallial progenitor domains by the combinatorial expression of transcriptional codes. J Neurosci 27:9682-9695.

Fogarty M, Grist M, Gelman D, Marín O, Pachnis V, Kessaris N (2007) Spatial genetic patterning of the embryonic neuroepithelium generates GABAergic interneuron diversity in the adult cortex. J Neurosci 27:10935-10946.

Grigoriou M, Tucker AS, Sharpe PT, Pachnis V (1998) Expression and regulation of Lhx6 and Lhx7, a novel subfamily of LIM homeodomain encoding genes, suggests a role in mammalian head development. Development 125:2063-2074.

Jackson AL, Burchard J, Leake D, Reynolds A, Schelter J, Guo J, Johnson JM, Lim L, Karpilow J, Nichols K, Marshall W, Khvorova A, Linsley PS (2006) Position-specific chemical modification of siRNAs reduces "off-target" transcript silencing. RNA 12:1197-1205.

Lavdas AA, Grigoriou M, Pachnis V, Parnavelas JG (1999) The medial ganglionic eminence gives rise to a population of early neurons in the developing cerebral cortex. J Neurosci 19:7881-7888.

Liodis P, Denaxa M, Grigoriou M, Akufo-Addo C, Yanagawa Y, Pachnis V (2007) Lhx6 activity is required for the normal migration and specification of cortical interneuron subtypes. J Neurosci 27:3078-3089.

Lopes da Silva S, Cox JJ, Jonk LJ, Kruijer W, Burbach JP (1995) Localization of transcripts of the related nuclear orphan receptors COUP-TF I and ARP-1 in the adult mouse brain. Brain Res Mol Brain Res 30:131-136.

López-Bendito G, Sturgess K, Erdelyi F, Szabo G, Molnar Z, Paulsen O (2004) Preferential origin and layer destination of GAD65-GFP cortical interneurons. Cereb Cortex 14:1122-1133.

Nagata I, Terashima T (1994) Migration behavior of granule cells on laminin in cerebellar microexplant cultures from early postnatal reeler mutant mice. Int J Dev Neurosci 12:387-395.

Nakajima K (2007) Control of tangential/non-radial migration of neurons in the developing cerebral cortex. Neurochem Int 51:121-131.

Nery S, Fishell G, Corbin JG (2002) The caudal ganglionic eminence is a source of distinct cortical and subcortical cell populations. Nat Neurosci 5:1279-1287.

Niwa H, Yamamura K, Miyazaki J (1991) Efficient selection for high-expression transfectants with a novel eukaryotic vector. Gene 108:193-199.

Park JI, Tsai SY, Tsai MJ (2003) Molecular mechanism of chicken ovalbumin upstream promoter-transcription factor (COUP-TF) actions. Keio J Med 52:174-181.

Puelles L, Kuwana E, Puelles E, Bulfone A, Shimamura K, Keleher J, Smiga S, Rubenstein JL (2000) Pallial and subpallial derivatives in the embryonic chick and mouse telencephalon, traced by the expression of the genes Dlx-2, Emx-1, Nkx-2.1, Pax-6, and Tbr-1. J Comp Neurol 424:409-438.

Rymar VV, Sadikot AF (2007) Laminar fate of cortical GABAergic interneurons is dependent on both birthdate and phenotype. J Comp Neurol 501:369-380.

Stenman J, Toresson H, Campbell K (2003) Identification of two distinct progenitor populations in the lateral ganglionic eminence: implications for striatal and olfactory bulb neurogenesis. J Neurosci 23:167-174.

Suh JM, Yu CT, Tang K, Tanaka T, Kodama T, Tsai MJ, Tsai SY (2006) The expression profiles of nuclear receptors in the developing and adult kidney. Mol Endocrinol 20:3412-3420.

Sussel L, Marin O, Kimura S, Rubenstein JL (1999) Loss of Nkx2.1 homeobox gene function results in a ventral to dorsal molecular respecification within the basal telencephalon: evidence for a transformation of the pallidum into the striatum. Development 126:3359-3370.

Tabata H, Nakajima K (2001) Efficient in utero gene transfer system to the developing mouse brain using electroporation: visualization of neuronal migration in the developing cortex. Neuroscience 103:865-872.

Tachikawa K, Sasaki S, Maeda T, Nakajima K (2008) Identification of molecules preferentially expressed beneath the marginal zone in the developing cerebral cortex. Neurosci Res 60:135-146.

Tole S, Remedios R, Saha B, Stoykova A (2005) Selective requirement of Pax6, but not Emx2, in the specification and development of several nuclei of the amygdaloid complex. J Neurosci 25:2753-2760.

Tripodi M, Filosa A, Armentano M, Studer M (2004) The COUP-TF nuclear receptors regulate cell migration in the mammalian basal forebrain. Development 131:6119-6129.

Wichterle H, Turnbull DH, Nery S, Fishell G, Alvarez-Buylla A (2001) In utero fate mapping reveals distinct migratory pathways and fates of neurons born in the mammalian basal forebrain. Development 128:3759-3771.

Willi-Monnerat S, Migliavacca E, Surdez D, Delorenzi M, Luthi-Carter R, Terskikh AV (2008) Comprehensive spatiotemporal transcriptomic analyses of the ganglionic eminences demonstrate the uniqueness of its caudal subdivision. Mol Cell Neurosci 37:845-856.

Wonders CP, Anderson SA (2006) The origin and specification of cortical interneurons. Nat Rev Neurosci 7:687-696.

Xu Q, Cobos I, De La Cruz E, Rubenstein JL, Anderson SA (2004) Origins of cortical interneuron subtypes. J Neurosci 24:2612-2622.

Xu Q, Tam M, Anderson SA (2008) Fate mapping Nkx2.1-lineage cells in the mouse telencephalon. J Comp Neurol 506:16-29.

You LR, Lin FJ, Lee CT, DeMayo FJ, Tsai MJ, Tsai SY (2005) Suppression of Notch signalling by the COUP-TFII transcription factor regulates vein identity. Nature 435:98-104.

Yozu M, Tabata H, Nakajima K (2004) Birth-date dependent alignment of GABAergic neurons occurs in a different pattern from that of nonGABAergic neurons in the developing mouse visual cortex. Neurosci Res 49:395-403.

Yozu M, Tabata H, Nakajima K (2005) The caudal migratory stream: a novel migratory stream of interneurons derived from the caudal ganglionic eminence in the developing mouse forebrain. J Neurosci 25:72687277. 